\title{
MEMODELKAN TINGKAT PENGANGGURAN TERBUKA DI INDONESIA
}

\author{
Kadek Yusa Mahendra ${ }^{1 \S}$, Made Susilawati ${ }^{2}$, Ni Luh Putu Suciptawati ${ }^{3}$ \\ ${ }^{1}$ Program Studi Matematika, Fakultas MIPA - Universitas Udayana [Email: yusamahendra67@gmail.com] \\ ${ }^{2}$ Program Studi Matematika, Fakultas MIPA - Universitas Udayana [Email: madesusilawati@unud.ac.id] \\ ${ }^{3}$ Program Studi Matematika, Fakultas MIPA - Universitas Udayana [Email: suciptawati@unud.ac.id] \\ ${ }^{\S}$ Corresponding Author
}

\begin{abstract}
Unemployment is one of the problems in the field in economic development. To determine the development of open unemployment in a region, an indicator of the open unemployment rate is used. The highest of open unemployment rate is Aceh Province and Maluku Province in 2015 at 9,93 percent and the lowest Bali Province in 2018 at 1,37 percent. The purpose of this work is to modeling and determine the significant factors that affect the open unemployment rate in Indonesia by applying spatial panel data regression. The results show indicate that there is no effect of spatial dependence on the model, so the model chosen to model the open unemployment rate in Indonesia is a panel data model with a fixed time effect and significant affect by head count index, the percentage of illiterate people, the provincial minimum wage, and the number of the workforce.
\end{abstract}

Keywords: Indonesia, Open Unemployment Rate, Spatial Panel Data Regression.

\section{PENDAHULUAN}

Pengangguran merupakan masalah yang sangat berhubungan dengan kemajuan pembangunan ekonomi suatu negara. Menurut Sukirno (1994) pengangguran terbuka tercipta karena adanya penambahan tenaga kerja yang banyak sedangkan lapangan pekerjaan yang tersedia sedikit. Dan menurut BPS Indonesia (2019) pengangguran terbuka merupakan seseorang yang tidak memiliki pekerjaan dan sedang mencari perkerjaan, dan ada juga yang sudah mempunyai pekerjaan, tetapi belum mulai bekerja. BPS Indonesia rutin mengadakan Survei Angkatan Kerja Nasional (SAKERNAS) setiap tahun untuk memperoleh berbagai data, salah satunya data tingkat pengangguran terbuka yang diharapkan menjadi salah satu acuan pemerintah untuk mengetahui tingkat keberhasilan program ketenagakerjaan di Indonesia.

Berdasarkan data BPS Indonesia (2019) tingkat pengangguran terbuka (TPT) di Indonesia secara umum dari periode 2015-2019 menunjukkan tren penurunan dan pada tahun 2019 angka TPT di Indonesia berada di angka $5,28 \%$. Walaupun demikian angka tersebut terbilang masih tinggi dibandingkan dengan angka TPT di beberapa negara tetangga. Indonesia berada diurutan ketiga tertinggi angka TPT setelah Brunei Darussalam dengan angka 8,7\% dan Filipina dengan angka 5,4\% (ASEAN Secretariat, 2019).

Penelitian sebelumnya terkait tingkat pengangguran terbuka dilakukan oleh Pratiwi dkk. (2019), metode statistika yang dipakai adalah analisis regresi dengan pendekatan data panel dengan variabel independen yang digunakan jumlah angkatan kerja, angka partisipasi kasar SMA, rasio ketergantungan, PDRB, UMK, jumlah penduduk pulau jawa, inflasi, dan IPM. Penelitian ini disimpulkan bahwa variabel independen yang memengaruhi TPT kabupaten/kota di pulau jawa yaitu jumlah angkatan kerja, rasio ketergantungan, dan IPM dengan menghasilkan nilai adjusted $R^{2}$ senilai $79,26 \%$, hal tersebut menerangkan variabel independen berpengaruh terhadap variabel dependen sebanyak 79,26\%, sedangkan variabel lain diluar variabel yang diteliti hanya berpengaruh $20,74 \%$ saja. Penelitian juga dilakukan oleh Ningtias \& Rahayu (2017) dengan metode analisis regresi spasial, variabel independen yang digunakan yaitu persentase penduduk miskin, PDRB berdasarkan lapangan usaha jasa lainnya, dan 
persentase jumlah angkatan kerja dengan pendidikan tertinggi tingkat diploma I/II/III/Akademi. Penelitian ini disimpulkan bahwa persentase penduduk miskin dan PDRB berdasarkan lapangan usaha jasa signifikan memengaruhi TPT Jawa Timur periode 2015. Serta Poyoh dkk. (2017) dengan analisis linier berganda yaitu penelitian Aspek yang memengaruhi tingkat pengangguran di Provinsi Sulawesi Utara, variabel independen yang digunakan adalah upah minimum kabupaten, tingkat inflasi, dan laju pertumbuhan PDRB. Pada penelitian tersebut disimpulkan semua variabel independen signifikan memengaruhi tingkat pengangguran di Provinsi Sulawesi Utara.

Bersumber pada penelitian sebelumnya mengenai faktor yang memengaruhi TPT, penulis mengambil dan menggabungkan beberapa aspek yang signifikan untuk diteliti, maka didapatkan variabel independen yang diteliti untuk penelitian ini yaitu pengaruh persentase penduduk miskin (HCI-P0), IPM, persentase penduduk buta huruf umur 15 tahun ke atas (PPBH), upah minimum provinsi (UMP), dan jumlah angkatan kerja (AK) terhadap TPT di Indonesia pada periode 20152019. Data berjenis panel yang akan diambil oleh penulis, data berjenis panel ini mencakup data waktu (tahun) dan data objek (provinsi).

Gabungan dari beberapa data individu (cross section) dan beberapa data dalam periode waktu (time series) disebut data panel, Untuk melihat kedua hubungan antara variabel independen dengan variabel dependen pada data berjenis panel digunakan analisis regresi data panel (Gujarati \& Porter, 2009). Greene (2012) mengungkapkan ada tiga jenis model pendekatan yang bisa digunakan dalam analisis regresi data dengan tipe panel yaitu, dengan pendekatan common effect model (CEM), fixed effect model (FEM), dan random effect model (REM)

Oleh para ahli, data berjenis panel ini dapat dikembangkan lagi menjadi model regresi data panel spasial karena diduga pada suatu wilayah variabel dependen atau galatnya memengaruhi wilayah lainnya, keadaan ini disebut dependensi spasial. Elhorst (2010) menjelaskan spatial lag model mengkaji tentang kebergantungan variabel dependen antarwilayah dan spatial error model mengkaji tentang kebergantungan dari error atau sisaan antarwilayah. Wilayah Indonesia diduga terdapat dependensi spasial antar Provinsi. Oleh karena itu teknik analisis yang digunakan regresi data berjenis panel spasial.

\section{METODE PENELITIAN}

\subsection{Jenis dan Sumber Data}

Pada penelitian ini menggunakan data sekunder dari periode 2015 sampai 2019 pada setiap Provinsi di Indonesia. Publikasi badan pusat statistik Indonesia merupakan sumber data penelitian ini.

\subsection{Variabel Penelitian}

Variabel dependen $\left(Y_{i t}\right)$ yang dipakai TPT dan variabel independen terdiri dari persentase penduduk miskin $\left(X_{1 i t}\right)$, indeks pembangunan manusia (IPM) $\left(X_{2 i t}\right)$, PPBH $\left(X_{3 i t}\right)$, upah minimum provinsi (UMP) $\left(X_{4 i t}\right)$, dan jumlah angkatan kerja $\left(X_{5 i t}\right)$.

\subsection{Tahapan Analisis}

Olah data menggunakan software R 3.6.3 dan langkah penelitian dijabarkan sebagai berikut:

1. Mengestimasi model CEM, FEM, dan REM.

\section{a. Common Effect Model (CEM)}

Diasumsikan intersep dan koefisien slope di unit cross section dan periode waktu (time series) tetap disebut CEM. Estimasi parameter dalam CEM adalah ordinary least square (OLS) (Baltagi, 2005). Secara umum persamaan modelnya sebagai berikut:

$$
\begin{gathered}
Y_{i t}=\alpha+\sum_{k=1}^{5} \beta_{k} X_{k i t}+u_{i t} ; \\
i=1,2, \ldots, 34 ; t=2015,2016, \ldots, 2019
\end{gathered}
$$

Dengan $\alpha$ adalah intersep, $\beta$ adalah slope berukuran $(K \times 1)$, dan $u$ adalah error berukuran $(N \times T) \times 1$.

\section{b. Fixed Effect Model (FEM)}

Pada CEM sering kali model yang dihasilkan tidak bisa menangkap individual heterogeneity pada masing-masing individu dan antar waktu, hal tersebut akan menyebabkan terjadinya bias pada model yang diperoleh. Oleh karena itu disarankan menggunakan FEM. FEM mengasumsikan bahwa intersep bersifat tidak konstan, artinya model FEM ini memerhatikan keberagaman antar individu dan waktu, sementara slope diasumsikan tetap antarunit 
individu dan periode waktu (Gujarati \& Porter, 2009). Persamaan model FEM:

$$
Y_{i t}=D \alpha_{i}+\sum_{k=1}^{5} \beta_{k} X_{k i t}+u_{i t}
$$

$$
i=1,2, \ldots, 34 ; t=2015,2016, \ldots, 2019
$$

Dengan $\alpha$ adalah intersep, $\beta$ adalah slope berukuran $(K \times 1), \quad D$ adalah matriks variabel dummy dan $u$ adalah error berukuran $(N \times T) \times 1$.

FEM dipisahkan menjadi 2 diantaranya fixed individual (FEM Individual) dan fixed time (FEM Time).

1. FEM Individual

$$
\begin{gathered}
Y_{i t}=\sum_{r=1}^{34} D_{r t} \alpha_{r}+\sum_{k=1}^{5} \beta_{k} X_{k i t}+u_{i t} ; \\
i=1,2, \ldots, 34 ; t=2015,2016, \ldots, 2019 \\
\text { Dengan } D_{r t}=1 \text { jika } r=i, D_{r t}=0 \text { jika } r \neq i .
\end{gathered}
$$

\section{FEM Time}

$$
\begin{array}{r}
Y_{i t}=\sum_{s=2015}^{2019} D_{i s} \alpha_{s}+\sum_{k=1}^{5} \beta_{k} X_{k i t}+u_{i t} \\
i=1,2, \ldots, 34 ; t=2015,2016, \ldots, 2019 \\
\text { Dengan } D_{i s}=1 \text { jika } s=t, D_{i s}=0 \text { jika } s \neq t .
\end{array}
$$

\section{c. Random Effect Model (REM)}

Apabila terjadi penambahan variabel bertipe dummy ke dalam FEM akan menyebabkan terjadinya penurunan angka derajat bebas, dalam hal ini parameter yang diestimasi menjadi tidak efisien, untuk mengatasinya munculah REM. REM mengansumsikan bahwa intersep merupakan variabel acak. Estimasi parameter pada REM menggunakan metode GLS (generalized least square). Secara umum persamaan modelnya sebagai berikut:

$$
Y_{i t}=\alpha_{0}+\sum_{k=1}^{5} \beta_{k} X_{k i t}+w_{i t}
$$$$
i=1,2, \ldots, 34 ; t=2015,2016, \ldots, 2019
$$

Dengan $\alpha$ adalah intersep, $\beta$ adalah slope berukuran $(K \times 1)$, dan $w$ adalah error gabungan terdiri dari $e_{i}+u_{i t}$.

2. Melakukan uji Chow dan uji Hausman untuk memilih model terbaik.

3. Melakukan uji signifikansi untuk mengetahui pengaruh antar parameter pada model regresi data berjenis panel terpilih.
4. Membentuk matriks pembobot inverse distance dan standarisasi baris matriks pembobotnya.

5. Melakukan uji Lagrange Multiplier pada model regresi data panel terpilih untuk melihat dependensi spasial. Bila terdapat dependensi spasial analisis dilanjutkan ke langkah 6. Dan bila tidak terdapat dependensi spasial, maka model yang terpilih model data panel, analisis selesai.

6. Maximum Likelihood Estimation digunakan untuk menduga parameter spasial pada model data panel terpilih.

7. Melakukan uji Wald untuk mengetahui pengaruh antar parameter pada model regresi data berjenis panel spasial terpilih.

8. Terpilih model yang cocok lakukan interpretasi pada modelnya.

\section{HASIL DAN PEMBAHASAN}

\subsection{Common Effect Model (CEM)} Tabel 1.

Hasil estimasi CEM ditampilkan oleh

Tabel 1. Estimasi common effect model

\begin{tabular}{|l|c|r|r|r|}
\hline Variabel & Parameter & $\begin{array}{c}\text { Nilai } \\
\text { Estimasi }\end{array}$ & $t_{\text {hitung }}$ & $p_{\text {value }}$ \\
\hline Intersep & $\alpha$ & 4,3577 & 3,2042 & 0,001627 \\
\hline HCI-P0 & $\beta_{1}$ & 0,0563 & 1,3489 & 0,179222 \\
\hline IPM & $\beta_{2}$ & $-0,3019$ & 2,0082 & 0,046260 \\
\hline PPBH & $\beta_{3}$ & 0,2658 & 8,0981 & $\begin{array}{r}1,203 \mathrm{e}- \\
13\end{array}$ \\
\hline UMP & $\beta_{4}$ & $-0,3302$ & 2,0478 & 0,042178 \\
\hline AK & $\beta_{5}$ & 0,1326 & 4,6550 & $\begin{array}{r}6,650 \mathrm{e}- \\
06\end{array}$ \\
\hline & & & $F_{\text {hitung }}$ & 17,0555 \\
\hline & & & $p_{\text {value }}$ & $\begin{array}{r}1,4533 \mathrm{e}- \\
13\end{array}$ \\
\hline & & & $R^{2}$ & $34,21 \%$ \\
\hline
\end{tabular}

Sumber: data diolah, 2020

\subsection{Fixed Effect Model (FEM)}

Dalam mengestimasi FEM Individual terdapat variabel dummy individu yang dalam penelitian ini berupa 34 Provinsi yang ada di Indonesia. Sementara, dalam FEM Time terdapat variabel dummy waktu berupa tahun yaitu tahun 2015 sampai 2019. Pada Tabel 2. Dan Tabel 3. memperlihatkan estimasi fixed individual effect model dan fixed time effect model sebagai berikut: 
Tabel 2. Estimasi fixed individual effect model

\begin{tabular}{|l|c|c|c|r|}
\hline Variabel & $\begin{array}{c}\text { Para- } \\
\text { meter }\end{array}$ & $\begin{array}{c}\text { Nilai } \\
\text { Estimasi }\end{array}$ & $t_{\text {hitung }}$ & $p_{\text {value }}$ \\
\hline Intersep & $\alpha_{i}$ & & & \\
\hline HCI-P0 & $\beta_{1}$ & $-0,0120$ & $-0,0664$ & 0,9471 \\
\hline IPM & $\beta_{2}$ & $-0,9088$ & $-1,3889$ & 0,1672 \\
\hline PPBH & $\beta_{3}$ & $-0,0858$ & $-0,4207$ & 0,6747 \\
\hline UMP & $\beta_{4}$ & $-0,1925$ & $-0,7282$ & 0,4678 \\
\hline AK & $\beta_{5}$ & $-0,6681$ & $-1,6895$ & 0,0935 \\
\hline & & & & \\
\hline & & & $F_{\text {hitung }}$ & 12,4968 \\
\hline & & & $p_{\text {value }}$ & 6,3549 \\
& & & $R^{2}$ & $32,29 \%$ \\
\hline & & & \multicolumn{2}{|r}{} \\
\hline
\end{tabular}

Sumber: data diolah, 2020

Tabel 3. Estimasi fixed time effect model

\begin{tabular}{|l|c|r|r|r|}
\hline Variabel & $\begin{array}{c}\text { Para- } \\
\text { meter }\end{array}$ & $\begin{array}{c}\text { Nilai } \\
\text { Estimasi }\end{array}$ & $t_{\text {hitung }}$ & $p_{\text {value }}$ \\
\hline Intersep & $\alpha_{t}$ & & & \\
\hline HCI-P0 & $\beta_{1}$ & 0,0979 & 2,5596 & 0,01141 \\
\hline IPM & $\beta_{2}$ & $-0,0146$ & $-0,8238$ & 0,41129 \\
\hline PPBH & $\beta_{3}$ & 0,2428 & 8,1384 & $1,06 \mathrm{e}-13$ \\
\hline UMP & $\beta_{4}$ & $-0,9520$ & $-5,361$ & $2,84 \mathrm{e}-07$ \\
\hline AK & $\beta_{5}$ & 0,1688 & 6,4084 & $1,57 \mathrm{e}-09$ \\
\hline & & & & \\
\hline & & & $F_{\text {hitung }}$ & 26,0064 \\
\hline & & & $p_{\text {value }}$ & $2,22 \mathrm{e}-16$ \\
\hline & & & $R^{2}$ & $44,83 \%$ \\
\hline
\end{tabular}

Sumber: data diolah, 2020

\subsection{Random Effect Model (REM)}

REM mengansumsikan bahwa intersep merupakan variabel acak. Estimasi parameter pada REM menggunakan metode GLS (generalized least square). Tabel 4.

Hasil estimasi model REM disajikan pada

Tabel 4. Estimasi Random Effect Model

\begin{tabular}{|l|c|r|r|r|}
\hline Variabel & $\begin{array}{c}\text { Parame } \\
\text { ter }\end{array}$ & $\begin{array}{c}\text { Nilai } \\
\text { Estimasi }\end{array}$ & $t_{\text {hitung }}$ & $p_{\text {value }}$ \\
\hline Intersep & $\alpha$ & 8,9328 & 3,7655 & 0,000166 \\
\hline HCI-P0 & $\beta_{1}$ & 0,0010 & 0,0129 & 0,989696 \\
\hline IPM & $\beta_{2}$ & $-0,6687$ & $-2,3792$ & 0,017350 \\
\hline PPBH & $\beta_{3}$ & 0,2841 & 4,3106 & $\begin{array}{r}1,628 \mathrm{e}- \\
05\end{array}$ \\
\hline UMP & $\beta_{4}$ & $-0,5091$ & $-3,5228$ & 0,000427 \\
\hline AK & $\beta_{5}$ & 0,0716 & 1,2505 & 0,211107 \\
\hline & & & $\chi_{\text {hitung }}^{2}$ & 55,9617 \\
\hline & & & $p_{\text {value }}$ & $8,28 \mathrm{e}-11$ \\
\hline & & & $R^{2}$ & $25,44 \%$ \\
\hline
\end{tabular}

Sumber: data diolah, 2020

\subsection{Pemilihan model data panel}

\section{a. Uji Chow}

Mempertimbangkan keberadaan intersep masing-masing Provinsi. Hipotesanya adalah:

$H_{0}: \alpha_{1}=\alpha_{2}=\cdots=\alpha_{34}$ (tidak ditemukan perbedaan intersep pada masing-masing Provinsi).

$H_{1}$ : minimal terdapat sepasang $\alpha_{i} \neq \alpha_{r}$ dengan $i, r=1,2, \ldots, 34$ (minimal terdapat sepasang Provinsi yang memiliki intersep berbeda)

Berdasarkan perhitungan, diperoleh bahwa nilai $p_{\text {value }}=2,2 \times 10^{-16}<\alpha_{0,05}$, berarti $\mathrm{H}_{0}$ ditolak, sehingga minimal terdapat dua intersep (Provinsi) yang berbeda. Oleh karena itu, model yang cocok adalah FEM.

\section{b. Uji Hausman}

Pada hal ini FEM dibandingkan dengan REM (Baltagi, 2005). Sebelum dilakukan pengujian, dilakukan pemilihan model FEM dengan memerhatikan nilai koefisien determinasi $\left(R^{2}\right)$ pada fixed individual effect model dan fixed time effect model yang ditemukan di Tabel 2. dan Tabel 3. Nilai koefisien determinasi $\left(R^{2}\right)$ pada fixed time effect model $(44,83 \%)>$ Nilai koefisien determinasi $\left(R^{2}\right)$ fixed individual effect model (32,29\%), sehingga pada uji Hausman FEM Time akan dibandingkan dengan REM. Hipotesis yang dipakai adalah:

$H_{0}: E\left(W_{i t} \mid X_{i t}\right)=0$ (REM konsisten)

$H_{1}: E\left(W_{i t} \mid X_{i t}\right) \neq 0$ (REM tidak konsisten)

Berdasarkan perhitungan, diperoleh bahwa nilai $p_{\text {value }}=2,2 \times 10^{-16}<\alpha_{0,05}$, sehingga $H_{0}$ ditolak. Dengan demikian FEM Time yang merupakan bagian dari FEM terpilih untuk digunakan.

\subsection{Pengujian Signifikansi Parameter}

Dalam penelitian ini, terdapat dua pengujian signifikansi yaitu secara simultan dan parsial. Dengan memerhatikan Tabel 3. secara simultan diperoleh nilai $p_{\text {value }}=$ $2,22 \times 10^{-16}<\alpha_{0,05}$ maka keputusannya $H_{0}$ ditolak. Hal tersebut berarti terdapat variabel independen dalam model yang berpengaruh terhadap variabel dependen.

Secara parsial dengan memerhatikan Tabel 3. terdapat empat variabel independen yang signifikan yaitu persentase penduduk miskin, persentase penduduk buta huruf, upah minimum provinsi, dan jumlah angkatan kerja. 


\subsection{Uji Kebergantungan Spasial}

Karena data penelitian mencakup wilayah diduga terdapat efek dependensi spasial antar wilayahnya. Untuk mengetahui efek dependensi spasial pada model data panel terpilih, dipakai uji Lagrange Multiplier (LM). Sebelum melakukan uji LM, terlebih dahulu membentuk matriks pembobot inverse distance. Setelah mendapatkan matriks pembobot inverse distance yang sudah dinormalisasi baris dilanjutkan dengan pengujian LM.

Hipotesa yang dipakai untuk spatial lag model: $H_{0}: \lambda=0$ (tidak ditemukan dependensi spasial di variabel dependen )

$H_{1}: \lambda \neq 0$ (ditemukan dependensi spasial di variabel dependen)

Sedangkan hipotesa yang dipakai untuk spatial error model:

$H_{0}: \rho=0$ (tidak ditemukan efek spasial pada galat)

$H_{1}: \rho \neq 0$ (ditemukan efek spasial pada galat)

Hasil kebergantungan spasial disajikan Tabel 5.

Tabel 5. Hasil Uji Lagrange Multiplier (LM)

\begin{tabular}{|l|c|c|}
\hline \multicolumn{1}{|c|}{ Model } & $\begin{array}{c}\text { Statistik } \\
\text { Uji LM }\end{array}$ & $p_{\text {value }}$ \\
\hline Spatial lag model & 2,8905 & 0,0891 \\
\hline Spatial error model & 1,9076 & 0,1672 \\
\hline
\end{tabular}

Sumber: data diolah, 2020

Pada Tabel 5. diperoleh bahwa spatial lag model dan spatial error model nilai $p_{\text {value }}>$ $\alpha_{0,05}$, sehingga keputusannya adalah $H_{0}$ diterima. Hal ini berarti tidak terdapat dependensi spasial pada taraf 5\%. Dengan tidak adanya dependensi spasial pada model FEM time effect, maka penelitian ini memakai model data berjenis panel dengan pendekatan FEM Time.

\subsection{Interpretasi Hasil}

Persamaan fixed time effect model sebagai berikut:

$$
\begin{aligned}
& Y_{i t}= \alpha_{t}+0,0979 X_{1 i t}-0,0146 X_{2 i t} \\
&+0,2428 X_{3 i t}-0,9520 X_{4 i t} \\
&+0,1688 X_{5 i t}+u_{i t} ; \\
& i=1,2, \ldots, 34 ; t=2015,2016, \ldots, 2019
\end{aligned}
$$

Dengan nilai intersep masing-masing tahun sebagai berikut:
Tabel 6. Nilai Intersep Setiap Tahun

\begin{tabular}{|c|c|}
\hline Parameter & Nilai Intersep \\
\hline$\alpha_{2015}$ & 1,9925 \\
\hline$\alpha_{2016}$ & 1,6863 \\
\hline$\alpha_{2017}$ & 1,6625 \\
\hline$\alpha_{2018}$ & 1,5470 \\
\hline$\alpha_{2019}$ & 1,4602 \\
\hline
\end{tabular}

Sumber: data diolah, 2020

Merujuk pada fixed time effect model diperoleh nilai koefisien determinasi sebesar 44,83 persen. Dimaksudkan bahwa kelima faktor yang digunakan mampu menjelaskan TPT sebanyak 44,83 persen dan dijelaskan oleh faktor lain sisanya diluar model. Nilai intersep dari tahun 2015 sampai tahun 2019 mengalami penurunan berarti tingkat pengangguran terbuka di Indonesia 5 tahun terakhir mengalami penurunan yang signifikan, maka dari itu pembangunan ekonomi di Indonesia pada 5 tahun terakhir berjalan baik. Sesuai dengan pernyataan Todaro (2004) mengatakan dilihat dari pertumbuhan ekonomi, struktur ekonomi, dan tingkat kesenjangan antar penduduk bisa menjadi tolak ukur keberhasilan pembangunan. Untuk mencapai keberhasilan tersebut dilakukan usaha-usaha selain mewujudkan pertumbuhan ekonomi yang tinggi, harus dibarengi dengan menghapus dan menurunkan tingkat kemiskinan, kesenjangan pendapatan, dan tingkat pengangguran.

Penelitian ini mendapatkan hasil bahwa persentase penduduk miskin, persentase penduduk buta huruf, upah minimum provinsi, dan jumlah angkatan kerja signifikan memengaruhi tingkat pengangguran terbuka negara Indonesia.

\section{KESIMPULAN DAN SARAN}

\subsection{Kesimpulan}

Model yang cocok digunakan yaitu model data berjenis panel dengan pendekatan FEM yaitu fixed time effect model dengan koefisien determinasi 44,83 persen.

Aspek-aspek yang signifikan berpengaruh terhadap TPT negara Indonesia adalah persentase penduduk miskin, persentase penduduk buta huruf, upah minimum provinsi, dan jumlah angkatan kerja. 


\subsection{Saran}

Dengan keterbatasan kemampuan variabel independen dalam penelitian ini menjelaskan tingkat pengangguran terbuka, untuk penelitian selanjutnya diharapkan menemukan faktor lain yang lebih berpeluang dalam menjelaskan tingkat pengangguran terbuka di Indonesia.

\section{DAFTAR PUSTAKA}

ASEAN Secretariat, 2019. ASEAN Statistical Yearbook 2019. Jakarta: ASEAN Secretariat.

Baltagi, B. H., 2005. Econometric Analysis of Panel Data. 3rd ed. Chicester: John Wiley \& Sons Ltd.

BPS Indonesia, 2019. Keadaan Ketenagakerjaan Indonesia Agustus 2019. Jakarta: Badan Pusat Statistik.

Elhorst, J. P., 2010. Spatial Panel Data Models. In: Handbook of Applied Spatial Analysis.

Berlin Heiderberg New York: Springer, p. Ch. C.2.

Greene, W. H., 2012. Econometric Analysis. 7th ed. New York: Prentice Hall.

Gujarati, D. N. \& Porter, D. C., 2009. Basics Econometrics. 5th ed. New York: The McGrow-Hill.

Ningtias, I. P. \& Rahayu, S. P., 2017. Pemodelan Faktor-Faktor yang Mempengaruhi Tingkat Pengangguran Terbuka di Provinsi Jawa Timur Tahun 2015 Menggunakan Regresi Spasial. Jurnal Sains dan Seni ITS, 6(2).

Poyoh, A., Kapantow, G. H. M. \& Mandel, J. R., 2017. Faktor-Faktor yang Mempengaruhi Tingkat Pengangguran di Provinsi Sulawesi Utara. E-Journal Unsrat, 13(1A), pp. 55-56.

Pratiwi, H., Prawastyorini, A. N. \& S., 2019. Analisis Data Panel pada Tingkat Pengangguran Terbuka Kabupaten/Kota di Pulau Jawa. Jurnal Matematika, Statistika, dan Komputasi UNHAS, 16(1), pp. 51-57

Sukirno, S., 1994. Pengantar Ekonomi Makro. Jakarta: PT. Raja Grasindo Perseda.

Todaro, Michael P., 2004. Pembangunan Ekonomi Di Dunia Ketiga. Edisi Kedua Terjemahan Haris Munandar. Jakarta: Erlangga. 